\title{
Tissue-specific modification of selenium concentration by acute and chronic dexamethasone administration in mice
}

\author{
BY CHIHO WATANABE, CHOONG-YONG KIM AND HIROSHI SATOH \\ Department of Environmental Health Sciences, Tohoku University School of Medicine, Sendai, \\ 980-77 Japan
}

(Received 17 July 1995-Revised 29 December 1995-Accepted 5 March 1997)

\begin{abstract}
Several clinical reports have shown changes in plasma Se concentration with corticosteroid treatments, but the results have been inconsistent. Few experimental studies have been done on this subject. In the present study the effect of dexamethasone (DEX) treatment on Se concentrations and activities of Se-dependent glutathione peroxidase (EC 1.11.1.9; SeGPX) were examined in adult male ICR mice. In the first experiment, DEX was given via drinking water containing 5 or $50 \mathrm{mg} \mathrm{DEX/l.}$ At 1 or 3 weeks of DEX treatment, mice were dissected and the Se concentrations as well as SeGPx activities in various tissues, including plasma, were determined. At 1 week the DEX-treated groups had significantly lower hepatic Se concentrations and significantly higher plasma and cerebral concentrations than the control group. The DEX-treated groups showed lower SeGPx activities in the hepatic cytosol and higher SeGPx activities in the plasma than the saline $(9 \mathrm{~g} \mathrm{NaCl} / \mathrm{l})$-treated group, in parallel with the changes in Se concentrations. At 3 weeks, neither hepatic nor plasma Se concentrations showed a significant change. In the second experiment, mice were injected subcutaneously with DEX and, thereafter, mice were food-deprived. The DEX-injected groups had higher plasma Se concentrations. A similar finding was obtained also when the DEX- or salineinjected mice were not food-deprived. Thus, the difference between the DEX-treated and control groups was possibly caused by redistribution of tissue Se. These results suggested that the effects of DEX on Se concentrations were tissue dependent and that the higher plasma Se observed in DEXtreated groups might be explained by the release of tissue Se into plasma as plasma SeGPx.
\end{abstract}

Selenium: Glutathione peroxidase: Dexamethasone

Se is an essential trace element in mammals, and several of its functions as a constituent of Se-specific proteins have been reported (Burk, 1993). Although the mechanisms of metabolic regulation for Se and selenoproteins are largely unknown, many factors, such as dietary intake of $\mathrm{Se}$ (Burk, 1993), exposure to toxic metals such as $\mathrm{Hg}$ (Watanabe et al. 1993), deficiency of other trace elements such as $\mathrm{Cu}$ (Olin et al. 1994), physical exercise (Singh et al. 1991), and acute illness (Hawker et al. 1990), are shown to influence the tissue concentration of the element.

Corticosteroids are among such factors and are reported to increase (Koskelo, 1990; Marano et al. 1990) or decrease (Peretz et al. 1988) plasma (or serum) Se concentrations in human subjects, although Smith et al. (1989) found no such effects. In these studies the type of corticosteroids, the dose and the duration of steroid treatment, and the disease of the patients varied and, thus, might have contributed to the different results. Despite such drawbacks, these clinical observations are interesting because they may reflect previously unknown effects of corticosteroids on Se metabolism. In view of the fact that large doses of corticosteroids affected metabolism of other trace elements, such as $\mathrm{Cu}$ (Yunice et al. 1981) and Zn (Cousins et al. 1986), and that physical exercise (Singh et al. 1991) and acute 
illness (Hawker et al. 1990), stimuli that trigger corticosteroid responses, affected Se metabolism, it seems possible that the corticosteroids affect Se metabolism. To examine this possibility, determination of Se concentrations in the tissues is needed.

To our knowledge there was only one experimental study that dealt with the effect of corticosteroid on tissue concentrations of Se (Peretz et al. 1988). This study indicated that administration of prednisolone to rats for 5 weeks resulted in a slight decrease in plasma Se concentration, with unchanged Se concentrations in the erythrocytes, liver, and bone. Prednisolone, however, has both glucocorticoid and mineralcorticoid activities (Tyrrell \& Baxter, 1987). Thus, the observed effects might be the net effects of these two different activities. In addition, no clear dose-response was demonstrated in this rat model (Peretz et al. 1988).

In the present study we examined the effect of dexamethasone (DEX), which is mostly devoid of mineralcorticoid activity (Tyrrell \& Baxter, 1987), on tissue Se concentrations in mice. The primary purpose of the study was to establish the effects of the glucocorticoid on Se concentrations of various tissues in a dose-dependent manner. For this purpose, effects of the steroid were evaluated in terms of Se concentrations not only in plasma but also in various tissues. It is possible that effects of DEX differ among various selenoproteins. To gain an insight into such possible differences in the effects of DEX among various selenoproteins, activities of Se-dependent glutathione peroxidase (EC 1.11.1.9; SeGPX) were determined as a possible representative of the various enzyme proteins. In addition, to evaluate the contribution of diet-derived Se on the tissue Se concentrations, effects of acute DEX treatment were examined with fed and food-deprived mice.

\section{MATERIALS AND METHODS}

\section{Animals}

Male 8-week-old Slc : ICR mice (Japan SLC Co. Ltd, Hamamatsu, Japan; body weight 30$40 \mathrm{~g}$ ) were used. Two to three mice were housed together in a plastic cage. The cages were placed in a temperature-controlled room $\left(23.5 \pm 1^{\circ}\right)$. The room was illuminated between 08.00 and 20.00 hours. Unless otherwise described, water and food (non-purified diet F-2; Funabashi Farms, Funabashi, Japan) were available ad libitum. The procedures of the experiment were reviewed and approved by the Committee of Animal Experimentation of Tohoku University School of Medicine.

\section{Chemicals}

Dexamethasone phosphate disodium and 2,3-diaminonaphthalene were purchased from Sigma Chemical Co. (St Louis, MO, USA). All other chemicals were purchased from Wako Pure Chemicals (Osaka, Japan).

\section{Expt 1. Dexamethasone via drinking water}

Three groups of mice (five to six per group) were given distilled water containing 0,5 , or $50 \mathrm{mg} \mathrm{DEX} / \mathrm{l}$ for 1 week, and three additional groups (five mice per group) were given 0 , 0.5 , or $5 \mathrm{mg} \mathrm{DEX} / 1$ for 3 weeks. Based on the water intakes, DEX intakes were estimated as: $0,1 \cdot 0-1.4,10-13 \mathrm{mg} / \mathrm{kg}$ per $\mathrm{d}$ for the 1 -week groups and $0,0 \cdot 1-0 \cdot 13,1 \cdot 2-2.1 \mathrm{mg} / \mathrm{kg}$ per $\mathrm{d}$ for the 3 -week groups, in ascending order of DEX dose respectively. Food intake was recorded every $3-4 \mathrm{~d}$. At the end of 1 or 3 weeks, blood was withdrawn from the jugular 
vein under light diethyl ether anaesthesia. After cervical dislocation, tissues were removed and frozen immediately. The tissues and separated plasma were stored at $-80^{\circ}$ for later Se and SeGPx analyses.

\section{Expt 2. Dexamethasone injection}

DEX was dissolved in saline $(9 \mathrm{~g} \mathrm{NaCl} / 1)$ and was given subcutaneously $(2 \mathrm{mg} / \mathrm{kg}$ body weight); the injection volume was $5 \mathrm{ml} / \mathrm{kg}$ body weight. All injections were given between 10.00-12.00 hours. Saline was injected into the control group. After injection, food was withdrawn to avoid the influence of diet-derived Se. At 3, 6, 12 or $24 \mathrm{~h}$ after injection, mice were anaesthetized and dissected as described previously. Another study of the acute effects of DEX was done in which feeding was continued after injection. In the latter study, a high-dose group $(20 \mathrm{mg} / \mathrm{kg})$ was also included.

\section{Assays}

Tissue concentrations of Se were determined fluorometrically after ashing the tissue samples with a mixture of nitrate and $\mathrm{HClO}_{4}$ (Watkinson, 1966). The precision and accuracy of the assay was assured by including a reference material, bovine liver (NIST \#1577a; National Institute of Standard and Technology, Washington, DC, USA). The CV for triplicate determinations were less than $2.5 \%$ and the determined values fell within the range of the certified value. Activities of SeGPx in the liver cytosol and plasma were determined by spectrophotometry (Paglia \& Valnetine, 1967) with $\mathrm{H}_{2} \mathrm{O}_{2}$ as the substrate at $30^{\circ}$. Protein was determined by the method of Lowry et al. (1951). The CV based on triplicate assays for tissue extracts were less than $3.5 \%$. To obtain the liver cytosol, the liver was homogenized in $10 \mathrm{vol}$. ice-cold isotonic sucrose and centrifuged at $105000 \mathrm{~g}$ for $1 \mathrm{~h}$ at $4^{\circ}$.

\section{Statistics}

Differences among the groups with different DEX doses were evaluated by one-way ANOVA. When the effect of DEX was statistically significant, Tukey-Kramer's Honestly Significant Difference test, a multiple comparison procedure (Statistical Analysis Systems, 1985), was applied for pair-wise comparison. In the pair-wise comparison where multiple groups were compared with a control group, the Dunnet (1955) test was applied. The significance level was $P<0.05$. For these statistical calculations, SYSTAT for the Macintosh (SYSTAT, 1992) was used.

\section{RESULTS}

\section{Expt 1}

The food consumption did not appear to differ among the groups, although values were not analysed statistically due to the small sample size (two to three cages per group). At 1 week, no significant difference in the body weight was observed among the groups; although in the high-dose group there was significant decrease in body weight during the 1week period (Table 1). The weights of the spleen and adrenal, both of which are known to be sensitive to DEX treatment (LaBorde et al. 1992), were substantially lower in the DEXtreated groups than in the controls. At 3 weeks the high-dose group had significantly lower 
Table 1. Expt 1. Body weight and organ weights of mice after 1 or 3 weeks of treatment with dexamethasone (DEX) in the drinking water $\dagger$

(Mean values and standard deviations)

\begin{tabular}{|c|c|c|c|c|c|c|c|c|c|c|c|c|c|}
\hline \multirow{3}{*}{$\begin{array}{l}\text { DEX } \\
\text { dose } \\
(\mathrm{mg} / 1)\end{array}$} & \multirow[b]{3}{*}{$n$} & \multicolumn{4}{|c|}{ Body wt (g) } & \multicolumn{8}{|c|}{ Wt of organs (mg) } \\
\hline & & \multicolumn{2}{|c|}{ Pretreatment } & \multicolumn{2}{|c|}{ Post-treatment } & \multicolumn{2}{|c|}{ Liver } & \multicolumn{2}{|c|}{ Cerebrum } & \multicolumn{2}{|c|}{ Spleen } & \multicolumn{2}{|c|}{ Adrenal } \\
\hline & & Mean & $\mathrm{SD}$ & Mean & SD & Mean & SD & Mean & SD & Mean & SD & Mean & SD \\
\hline \multicolumn{14}{|l|}{1 week } \\
\hline 0 & 6 & $37 \cdot 1$ & 1.9 & 37.7 & 2.4 & 2010 & 206 & 276 & 18 & $118^{\mathrm{a}}$ & 19 & $8^{a}$ & 1 \\
\hline 5 & 5 & 37.2 & 3.3 & $35 \cdot 6$ & 2.9 & 2022 & 190 & 264 & 20 & $39^{\mathrm{b}}$ & 3 & $4^{b}$ & 1 \\
\hline 50 & 6 & 38.4 & $2 \cdot 3$ & $35 \cdot 4^{*}$ & $2 \cdot 3$ & 2183 & 331 & 265 & 26 & $30^{b}$ & 4 & $5^{b}$ & 1 \\
\hline \multicolumn{14}{|c|}{ Statistical significance of effect of DEX } \\
\hline (ANOVA) & & \multicolumn{2}{|c|}{ NS } & \multicolumn{2}{|c|}{ NS } & \multicolumn{2}{|c|}{ NS } & \multicolumn{2}{|c|}{ NS } & \multicolumn{2}{|c|}{$P<0.001$} & \multicolumn{2}{|c|}{$P<0.001$} \\
\hline \multicolumn{14}{|l|}{3 weeks } \\
\hline 0 & 5 & 37.5 & 0.7 & $43 \cdot 4^{\mathrm{a} *}$ & 1.8 & $2351^{\mathrm{a}}$ & 171 & $285^{\mathrm{a}, \mathrm{b}}$ & 20 & $137^{\mathrm{a}}$ & 14 & $7^{\mathbf{a}}$ & 2 \\
\hline 0.5 & 5 & 38.6 & 0.5 & $42 \cdot 0^{\mathrm{a} *}$ & 2.3 & $2091^{\mathrm{a}}$ & 205 & $306^{\mathrm{a}}$ & 21 & $99^{b}$ & 20 & $6^{\mathrm{a}}$ & 1 \\
\hline 5 & 5 & 37.8 & 1.8 & $36 \cdot 6^{\mathrm{b}} *$ & 1.5 & $1867^{b}$ & 264 & $255^{\mathrm{b}}$ & 16 & $40^{c}$ & 4 & $4^{b}$ & 0 \\
\hline \multicolumn{14}{|c|}{ Statistical significance of effect of DEX } \\
\hline (ANOVA) & & \multicolumn{2}{|c|}{ NS } & \multicolumn{2}{|c|}{$P<0.001$} & \multicolumn{2}{|c|}{$P<0.05$} & \multicolumn{2}{|c|}{$P<0.01$} & \multicolumn{2}{|c|}{$P<0.001$} & \multicolumn{2}{|c|}{$P<0.01$} \\
\hline
\end{tabular}

Mean values were significantly different from the corresponding pretreatment value (paired $t$ test): ${ }^{*} P<0 \cdot 05$.

a.b.c Mean values in the same column within 1-week and 3-week groups with unlike superscript letters were significantly different (Tukey-Kramer's test; $P<0.05$ ).

$\dagger$ For details of animals and procedures, see pp. 502-503.

body weights than the other groups. The spleen weights were significantly lower in both DEX-treated groups compared with the control group; in addition, the adrenal and liver weights were significantly lower in the high-dose group than in the other groups.

The Se concentration in the plasma was significantly higher in one DEX-treated group $(5 \mathrm{mg} / \mathrm{l})$ at 1 week, and this occurred in the absence of haemoconcentration (i.e. elevation of PCV) (Table 2). SeGPx activity in the plasma was higher in some DEX-treated groups when the activity was expressed both per unit plasma volume and per unit protein, and the difference appeared to be dose-dependent. Thus, although the concentration of plasma protein was higher in DEX-treated groups than in the control group, the difference in the plasma protein only partly explained the difference in SeGPx activity. The mean values for SeGPx : Se for the three doses of DEX $(0,5$ and $50 \mathrm{mg} / \mathrm{l}$ ) were 0.24 (SD 0.02), 0.26 (SD 0.05 ) and 0.31 (SD 0.05) respectively, thus tending to increase with increasing DEX dose, although the differences did not reach statistical significance $(P=0.067)$. At 3 weeks the non-significant upward trend in plasma Se concentrations with increasing dose of DEX appeared to be associated with haemoconcentration.

Hepatic Se was significantly lower in DEX-treated groups than in the control at 1 week (Table 3). This also held true for the cytosolic Se. The SeGPx activity in the hepatic cytosol was also significantly lower in DEX-treated groups than in the controls. The mean values for cytosolic SeGPx : cytosolic Se were 5.5 (SD 0.5), 4.9 (SD 0.5), and 4.8 (SD 0.2) for groups given water containing 0,5 , and $50 \mathrm{mgDEX} / 1$ respectively; the value for the $50 \mathrm{mg} / \mathrm{l}$ group was significantly lower than those for the other groups by Tukey-Kramer's test $(P<0.05)$. At 3 weeks, DEX-treated groups had lower mean hepatic Se values than the controls but the difference was not significant.

In mice treated with $50 \mathrm{mgDEX} / 1$ for 1 week, cerebral Se concentrations were significantly higher than those in the control group (2.74 (SD 0.12) v. 2.50 (SD 
Table 2. Expt 1. Selenium concentration and activity of selenium-dependent glutathione peroxidase (EC 1.11.1.9; SeGPX) in plasma after 1 or 3 weeks of treatment with dexamethasone $(D E X)$ in the drinking water*

(Mean values and standard deviations)

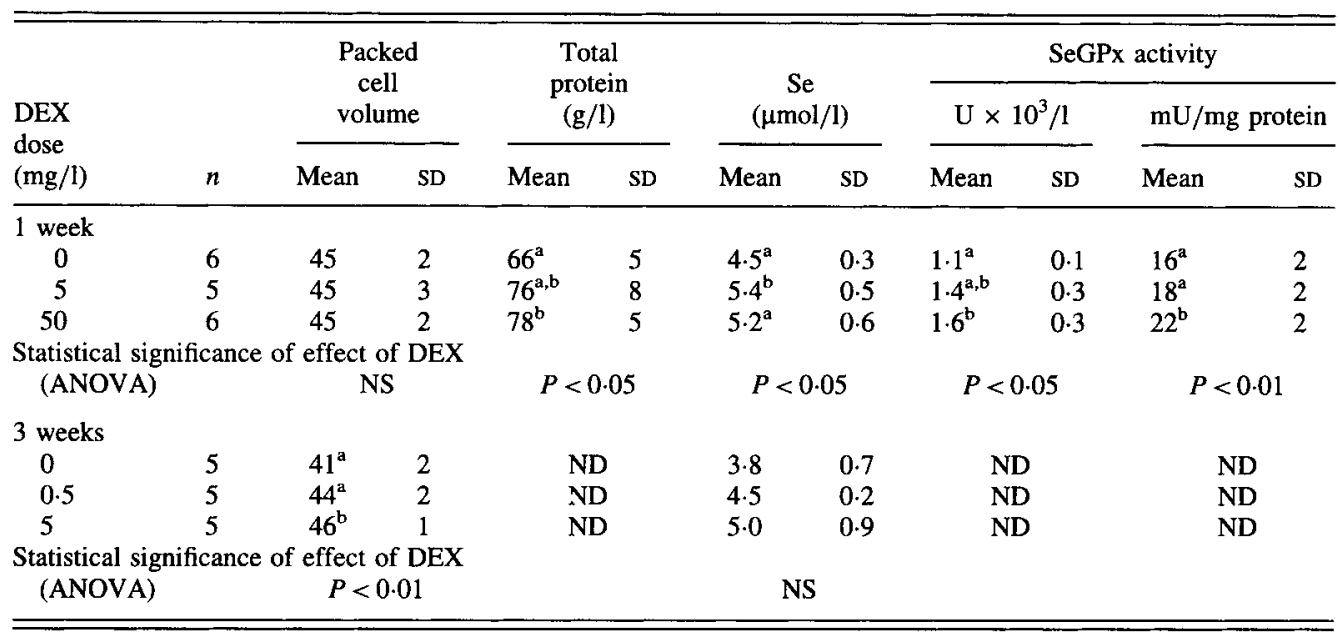

ND, not determined.

${ }^{a, b}$ Mean values in the same column within 1-week and 3-week groups with unlike superscript letters were significantly different (Tukey-Kramer's test; $P<0.05$ ).

* For details of animals and procedures, see pp. 502-503.

Table 3. Expt 1. Selenium concentration and activity of selenium-dependent glutathione peroxidase (EC 1.11.1.9; SeGPx) in the liver after 1 or 3 weeks of treatment with dexamethasone (DEX) in the drinking water*

(Mean values and standard deviations)

\begin{tabular}{|c|c|c|c|c|c|c|c|}
\hline \multirow[b]{2}{*}{ DEX dose (mg/l) } & \multirow[b]{2}{*}{$n$} & \multicolumn{2}{|c|}{$\begin{array}{l}\text { Whole tissue Se } \\
\text { ( } \mu \mathrm{mol} / \mathrm{kg} \text { tissue })\end{array}$} & \multicolumn{2}{|c|}{$\begin{array}{c}\text { Cytosolic Se } \\
(\mu \mathrm{mol} / \mathrm{kg} \text { tissue })\end{array}$} & \multicolumn{2}{|c|}{$\begin{array}{c}\text { Cytosolic } \\
\text { SeGPx } \\
\text { (U/mg protein) }\end{array}$} \\
\hline & & Mean & SD & Mean & SD & Mean & SD \\
\hline \multicolumn{8}{|l|}{1 week } \\
\hline 0 & 6 & $18 \cdot 8^{\mathrm{a}}$ & 0.9 & $11.4^{\mathrm{a}}$ & $1 \cdot 1$ & $0.72^{\mathrm{a}}$ & 0.06 \\
\hline 5 & 5 & $14 \cdot 5^{b}$ & 0.9 & $8 \cdot 6^{\mathrm{b}}$ & $1 \cdot 3$ & $0 \cdot 51^{b}$ & 0.05 \\
\hline 50 & 6 & $12 \cdot 8^{\mathrm{b}}$ & 1.6 & $8 \cdot 1^{b}$ & 0.5 & $0.48^{b}$ & 0.06 \\
\hline \multicolumn{8}{|c|}{ Statistical significance of effect of DEX } \\
\hline (ANOVA) & & \multicolumn{2}{|c|}{$P<0.001$} & \multicolumn{2}{|c|}{$P<0.001$} & \multicolumn{2}{|c|}{$P<0.001$} \\
\hline \multicolumn{8}{|l|}{3 weeks } \\
\hline 0 & 5 & $17 \cdot 1$ & 1.5 & \multicolumn{2}{|c|}{ ND } & \multicolumn{2}{|c|}{ ND } \\
\hline 0.5 & 5 & $16 \cdot 0$ & 1.9 & \multicolumn{2}{|c|}{ ND } & \multicolumn{2}{|c|}{ ND } \\
\hline 5 & 5 & 15.0 & 1.7 & \multicolumn{2}{|c|}{ ND } & \multicolumn{2}{|c|}{ ND } \\
\hline \multicolumn{6}{|c|}{$\begin{array}{l}\text { Statistical significance of effect of DEX } \\
\text { (ANOVA) }\end{array}$} & & \\
\hline
\end{tabular}

ND, not determined.

${ }^{a, b}$ Mean values in the same column within the 1-week group with unlike superscript letters were significantly different (Tukey-Kramer's test; $P<0.05$ ).

* For details of animals and procedures, see pp. 502-503. 
$0.10) \mathrm{nmol} / \mathrm{g} ; P<0.01$ ), but in other tissues, including kidney, muscle, heart, as well as cerebellum and brain stem, Se concentrations were not affected by DEX treatment (values not shown).

\section{Expt 2}

Among the food-deprived groups, plasma Se levels of the DEX-treated group were higher at 3 and $6 \mathrm{~h}$ after injection than those for the control group (Table 4). The plasma Se in the control groups continued to increase with time, while such changes were not observed in DEX-treated groups. Among the fed groups, DEX-treated groups had higher Se concentrations at both 6 and $24 \mathrm{~h}$ after injection. Neither tissue Se concentration nor PCV was affected by the DEX treatment in this acute experiment, regardless of feeding status (values not shown).

\section{DISCUSSION}

The results showed that 1 week of treatment with DEX affected tissue Se and SeGPX activity in a tissue-specific manner; i.e. Se and SeGPx activity in DEX-treated groups, in comparison with the control, was higher in plasma and lower in liver, while Se in cerebrum was higher. In most cases the differences tended to be dose-dependent. Because it is known that most of the Se in mammalian tissues, including plasma, binds to Se-specific proteins in which Se exists as selenocystein residue (Burk, 1993), the observed differences were likely to reflect the concentrations of some of these selenoproteins.

The differences in plasma and hepatic Se concentrations were less remarkable at 3 weeks than at 1 week. Because DEX-treated groups had lower spleen and adrenal weights at both 1 and 3 weeks, the change could not be ascribed to altered metabolism of DEX, e.g.

Table 4. Expt 2. Selenium concentration in plasma at 3-24h after treatment with dexamethasone (DEX) by injection $\dagger$

(Mean values and standard deviations)

\begin{tabular}{|c|c|c|c|c|c|c|c|c|c|c|c|}
\hline \multirow{3}{*}{$\begin{array}{l}\text { Period after DEX } \\
\text { injection }(\mathrm{h}) \ldots \\
\text { DEX dose }(\mathrm{mg} / \mathrm{kg})\end{array}$} & \multirow[b]{3}{*}{$n$} & \multicolumn{10}{|c|}{ Se concentration $(\mu \mathrm{mol} / \mathrm{l})$} \\
\hline & & \multicolumn{2}{|c|}{0} & \multicolumn{2}{|c|}{3} & \multicolumn{2}{|c|}{6} & \multicolumn{2}{|c|}{12} & \multicolumn{2}{|c|}{24} \\
\hline & & Mean & SD & Mean & SD & Mean & SD & Mean & SD & Mean & SD \\
\hline \multicolumn{12}{|l|}{ Food-deprived } \\
\hline 0 & 4 & $4 \cdot 4$ & 0.4 & $4 \cdot 1$ & $0 \cdot 1$ & $4 \cdot 3$ & 0.2 & $4.9^{*}$ & 0.2 & $5.4 *$ & 0.3 \\
\hline 2 & 4 & & & 4.5 & 0.5 & $5 \cdot 0$ & 0.2 & 4.8 & 0.4 & 4.7 & 0.3 \\
\hline \multicolumn{12}{|c|}{ Statistical significance of effect of DEX } \\
\hline (ANOVA) & & & & \multicolumn{2}{|c|}{$P<0.05$} & \multicolumn{2}{|c|}{$P<0.01$} & \multicolumn{2}{|c|}{ NS } & \multicolumn{2}{|c|}{$P<0.05$} \\
\hline \multicolumn{12}{|l|}{ Fed } \\
\hline 0 & 6 & \multicolumn{2}{|c|}{ ND } & \multicolumn{2}{|c|}{ ND } & $3.9^{\mathrm{a}}$ & 0.2 & \multicolumn{2}{|c|}{ ND } & $3 \cdot 7^{\mathrm{a}}$ & 0.3 \\
\hline 2 & 6 & & & \multicolumn{2}{|c|}{ ND } & $4 \cdot 3^{b}$ & 0.5 & \multicolumn{2}{|c|}{ ND } & $4.0^{\mathrm{a}, \mathrm{b}}$ & 0.2 \\
\hline 20 & 6 & & & \multicolumn{2}{|c|}{ ND } & $4 \cdot 4^{\mathrm{b}}$ & 0.3 & \multicolumn{2}{|c|}{ ND } & $4 \cdot 2^{\mathrm{b}}$ & 0.5 \\
\hline \multicolumn{12}{|c|}{ Statistical significance of effect of DEX } \\
\hline \multicolumn{4}{|c|}{ (ANOVA) } & \multicolumn{6}{|c|}{$P<0.05$} & \multicolumn{2}{|c|}{$P<0.05$} \\
\hline
\end{tabular}

ND, not determined.

Mean values were significantly different from $0 \mathrm{~h}$ (untreated) group (Dunnet test): ${ }^{*} P<0.05$.

${ }_{a, b}$ Mean values in the same column within the fed group with unlike superscript letters were significantly different (Tukey-Kramer's test; $P<0.05$ ).

$\dagger$ For details of animals and procedures, see pp. 502-503. 
enhanced inactivation during the continuous treatment. Instead, it was more likely that the specific action, if any, of DEX on Se metabolism was obscured by an enhanced general catabolism, as evidenced by the significantly lower body weight and liver weight of the high-dose group at 3 weeks. Such enhanced catabolism has also been reported in rats (Bryson \& Reynolds, 1981; LaBorde et al. 1992).

In the mice given $50 \mathrm{mg} \mathrm{DEX} / 1$ for 1 week, the difference in GPx activity $(45 \%$; relative to the control group) was much larger than the relative difference in $\mathrm{Se}$ concentration $(15 \%)$. In primates and rodents the percentage of plasma Se associated with SeGPx was estimated to range from less than 20 (Avissar et al. 1989; Deagen et al. 1993) to as high as 47 (Takahashi et al. 1987). If we assume that these values hold for mice and that the GPx activity reflects the amount of enzyme protein, as was confirmed in human plasma (Avissar et al. 1989), the observed difference in GPx, $45 \%$, would result in 9-21\% difference in plasma Se concentration. This is consistent with the observed difference of $15 \%$ in Se concentration. Thus, it is plausible that the observed difference in plasma Se, at least partly, reflected the difference in the amount of GPx-associated Se. From the present results it was not determined whether the concentration of the selenoprotein $\mathrm{P}$, which accounts for more than half the plasma Se in rats (Burk, 1993), was changed by DEX.

In the liver, both Se and the activity of the cytosolic SeGPx, a distinct protein from the plasma or 'extracellular' SeGPx, were lower in DEX-treated groups at 1 week. A decrease in SeGPx activity may result either from inactivation of existing enzyme or from a decrease in the amount of the enzyme protein. Because the 'cellular' SeGPx is a major selenoprotein in the liver of rats (Behne \& Wolters, 1983) and mice (Bansal et al. 1989) the parallel changes in the SeGPx activity and Se suggest that the latter was the case. It follows that the smaller SeGPx : Se value in the DEX-treated group indicated a selective decrease in SeGPx relative to other selenoproteins. Differential regulation of the levels of various selenoproteins has been reported; for example, the uptake of Se by SeGPx relative to other selenoproteins was suppressed in Se-deficient rats (Behne et al. 1988; Yang et al. 1989).

The results of the acute DEX study indicated that the difference in plasma Se between the DEX-treated group and the control group was not directly attributable to dietary Se, because the difference was observed not only in fed but also in food-deprived groups. If the higher plasma Se was due to a difference in GPx-associated Se, either the release of this enzyme into plasma or its removal from the plasma may have changed. In the former case the kidney or the heart might be the source of Se because the mRNA of this enzyme was detected in these organs but not in the liver in mice (Chu et al. 1992). On the other hand, it was speculated that increased plasma $S e$ in human patients treated with glucocorticoids was due to a reduced renal excretion of this element (Marano et al. 1990). To examine these alternatives, the uptake and release of Se by these organs and renal excretion of Se need to be measured rather than the steady-state concentration of Se.

The increase in plasma Se with time observed among the food-deprived control groups is noteworthy. Plasma Se was reported to show no diurnal variation in fed rats (Finley \& Kincaid, 1991), and we confirmed this observation with mice in a separate experiment (values not shown). Also in the present study, no difference was observed between the two fed control groups $(6 v .24 \mathrm{~h})$. Thus, the increase in the food-deprived mice must be associated with fasting. Although the mechanism of this increase is currently unknown, it might be associated with mobilization of lipids and/or proteins as energy substrates during fasting. Because the pattern of the change in plasma Se concentration with time was substantially different between the food-deprived DEX-treated and the control groups, it is deduced that the mechanism by which the food deprivation affected plasma Se differed from that of the DEX treatment. 
The clinical relevance of these observations is several-fold. First, the plasma Se levels under particular circumstances, such as DEX treatment, would not necessarily reflect the Se concentrations in vital organs, e.g. the liver. In such situations, plasma Se levels have to be interpreted cautiously. Second, the effects of DEX on tissue Se concentrations depended on the length of DEX treatment. This may partly explain the discrepancies between various clinical reports as well as the discrepancy between the report on rats (Peretz et al. 1988) and the present study. Third, if DEX affected the metabolism of SeGPx, as suggested by the present results, the effects should vary between individuals having different dietary habits, because the percentage of GPx-associated Se in the plasma varied with the form of Se in the diet (Deagan et al. 1993). This may be another reason for the inconsistent results reported in different clinical studies, since the dietary habits of the study subjects presumably varied.

\section{REFERENCES}

Avissar, N., Whitin, J. C., Allen, P. Z., Palmer, I. S. \& Cohen, H. J. (1989). Antihuman plasma glutathione peroxidase antibodies: immunologic investigations to determine plasma glutathione peroxidase protein and selenium content in plasma. Blood 73, 318-323.

Bansal, M., Oborn, C., Danielson, K. \& Medina, D. (1989). Evidence for two selenium-binding proteins distinct from glutathione peroxidase in mouse liver. Carcinogenesis 10, 541-546.

Behne, D., Hilmert, H., Scheid, S., Gessner, H. \& Elger, W. (1988). Evidence for specific selenium target tissues and new biologically important selenoproteins. Biochimica et Biophysica Acta 966, 12-21.

Behne, D. \& Wolters, W. (1983). Distribution of selenium and glutathione peroxidase in the rat. Journal of Nutrition 113, 456-461.

Bryson, G. \& Reynolds, R. W. (1981). Effects of adrenocortical stress responses and metabolic functions during and after long-term administration of dexamethasone to adult Evans-Long rats. Research Communications in Chemical Pathology and Pharmacology 34, 267-286.

Burk, R. (1993). Regulation of selenoproteins. Annual Review of Nutrition 13, 65-81.

Chu, F. F., Esworthy, R. S., Doroshow, J. H., Doan, K. \& Liu, X. F. (1992). Expression of plasma glutathione peroxidase in human liver in addition to kidney, heart, lung, and breast in humans and rodents. Blood 79, 3233-3238.

Cousins, R. J., Dunn, M. A., Leinart, A. S., Yedinak, K. C. \& DiSilvestro, R. A. (1986). Coordinate regulation of zinc metabolism and metallothionein gene expression in rats. American Journal of Physiology 251, E688E694.

Deagen, J., Butler, J., Zachara, B. \& Whanger, P. (1993). Determination of the distribution of selenium between glutathione peroxidase, selenoprotein P, and albumin in plasma. Analytical Biochemistry 208, 176-181.

Dunnet, C. (1955). A multiple comparison procedure for comparing several treatments with a control. American Statistical Association Journal 50, 1096-1121.

Finley, J. \& Kincaid, P. (1991). Effect of sex and time of sampling on selenium and glutathione peroxidase activity in tissues of mature rats. Biological Trace Element Research 29, 181-191.

Hawker, F., Stewart, P. \& Snitch, P. (1990). Effects of acute illness on selenium homeostatis. Critical Care Medicine 18, 442-446.

Koskelo, E. K. (1990). Serum selenium in children during anti-cancer chemotherapy. European Journal of Clinical Nutrition 44, 799-802.

LaBorde, J. B., Hansen, D. K., Young, J. F., Sheehan, D. M. \& Holson, R. R. (1992). Prenatal dexamethasone exposure in rats: effects of dose, age at exposure, and drug-induced hypophagia on malformations and fetal organ weights. Fundamental and Applied Toxicology 19, 545-554.

Lowry, O. H., Rosebrough, N. J., Farr, A. L. \& Randall, R. J. (1951). Protein measurement with the folin phenol reagent. Journal of Biological Chemistry 193, 265-275.

Marano, G., Fischioni, P., Graziano, C., Iannone, M. \& Morisi, G. (1990). Increased serum selenium levels in patients under corticosteroid treatment. Pharmacology and Toxicology 67, 120-122.

Olin, K., Walter, R. \& Keen, C. (1994). Copper deficiency affects selenoglutathione peroxidase and selenodeiodinase activities and antioxidant defense in weanling rats. American Journal of Clinical Nutrition 59, 654-658.

Paglia, D. E. \& Valnetine, W. N. (1967). Studies on the quantitative and qualitative characterization of erythrocyte glutathione peroxidase in developing rat brain. Journal of Laboratory and Clinical Medicine $\mathbf{7 0}$, $158-169$. 